\title{
Figüratif Resme Geri Dönüşün Nedenleri ve Etkileri ${ }^{1}$
}

\author{
Serpil Yayman ATASEVEN \\ Giresun Üniversitesi Ĕgitim Fakültesi \\ yayman_@hotmail.com
}

\begin{abstract}
$\ddot{O} z e t$
Plastik sanatlarda yaşanan büyük değişimler 20. yüzyllın ilk yarısında kendini hissettirmeye başlamıştır. Bu değişimlerin temelini Avant-Garde sanata bağl kavram ve düşünceler oluşturmuştur. Sanat, artik kendini sorgulayan, var olan tanimlar tekrar ele alan, felsefenin temel görevi olan, kavram üretmek işini üstlenmiștir. Modernizmle birlikte ortaya çıkan kavramlar 20. yüzyıl boyunca sanatı biçimlendirmişstir. Modernizmin savunduğu makine estetiği ve endüstrinin, sanat mitosunu ortadan kaldırmasıyla baş̧ka bir boyuta varmışıtır. Modernizme bağlı bu gelişmeler geleneksel sanatın o güne kadar geçerli olan tüm kurallarını yı kmıştır.

Teknolojik gelişmeler ile birlikte seri üretimin artması sanatı da etkilemiştir. Pop art hazır yapıtları konu olarak değil, biçimsel olarak kullanmıștır. Kapitalizm de, sanatın paraya dönüş̧ürü̈lmesi, sanatın sonsuzluk olarak adlandırllan gizli gücü̈n̈ ortadan kaldırmıştır. Bu nedenle Kavramsal Sanat, sanat nesnesini yok ederek bunu engellemeye çalıșmış ama bir süre sonra kendisi de sanat pazarının içine girmekten kurtulamamıștır. Sanat yapıtı kapitalist toplumda meta durumuna düşmekten kurtulamamıştır. Kavramsal Sanat, modernizmde olduğu gibi güzellik düşüncesini yadsımış, yargl ve duyguların yasalaşttğl evrensel bir varoluşa önem vermiştir. Bu nedenle tuval resminin biçimsel yapısl yerini dil ve sembollere birakmıştır. Sanat ve sanat olmayan arasındaki ayrımın belirsizliği eleştirel tavrın çözülmesi ile son bulmuştur.
\end{abstract}

Anahtar Kelimeler: figür, kapitalizm, kavramsal sanat, sanatçı.

\section{Causes and Effects of Returning The Filgurative Art}

\begin{abstract}
Great changes taking place in the plastic arts have begun to make itself felt in the first half of the 20th century. Concepts and ideas connected to avant-garde art have created the basic of these changes. Art has undertaken the job of investigating itself, adressing the existing definition and producing concept, the main task of philosophy. Concepts which have come up with modernism have formatted the art throughout 20th century. Machine aesthetic and industry that modernism defended have reached another dimension with eliminating the myth of art. The developments related to modernism have broken all the rules of traditional art which applied until the day.

Increasing mass production with technological developments has affected art, as well. Pop art has used available works of art stylistically not subjectively. Moreover, capitalism has eliminated the power of art called eternity based on monetization of art. For this reason, conceptual art has tried to prevent from this with ignoring art object but after a while it was not able to save itself from being part of art market. Conceptual art has cared a universal existence enacting judgement and emotion with denying the idea of beauty as in modernism. Therefore, formal structure of canvas painting has replaced with language and symbol. Uncertainty of discrimination between artistic and inartistic ones has ended up with solving the critical attitude.
\end{abstract}

Key Words: artist, capitalism, conceptual art, figure.

\footnotetext{
${ }^{1}$ Bu araştırmada elde edilen bulguların tamamı 12-14 Kasım 2015 tarihleri arasından düzenlenen "Felsefe, Eğitim ve Bilim Tarihi” adlı sempozyumda sözlü bildiri olarak sunulmuştur.
} 
Bu araştırmada elde edilen bulguların bir bölümü veya tamamı 12-14 Kasım 2015 tarihleri arasından düzenlenen "Felsefe, Eğitim ve Bilim Tarihi" adlı sempozyumda sözlü bildiri olarak sunulmuştur.

\section{Giriş}

Modern sanat, 1850'lerden günümüze uzanan bir süreci kapsamaktadır. Bu süreçte oluşan sanat alanındaki gelişmeler 1960'larda birbirinden farklı akım, eğilim ve gruplarla belirginlik kazanmıştır. Bu nedenle 1960'lı yıllar, modern sanatın kendine özgü dönemlerinden biri olarak kabul edilmiştir. Özellikle biçim ve içerik açısından farklılık gösteren bu akım ve gruplar, Pop Art, Op Art, Hiper-Gerçekçilik, Minimalizm, Kavramsal Sanat ile Happening, Eksantrik eylem (toprak sanat1), Grafiti sanatı olarak sıralanabilir. Aynı yıllarda dünyada siyasal ve sosyal açıdan çeşitli değişimler yaşanmıştır. ABD'nin Küba'ya saldırısı ile Vietnam Savaşı'nın başlaması, 1961 yazında Berlin Duvarı'nın örülmesi sonucunda Almanya'nın ikiye bölünmesi, işçi grevleri, hippiler, gençliğin liberal dünya görüşleri ile yaşam koşullarına yönelttikleri eleştirilerin yoğunlaşması sonucu oluşan beat generation (beat kuşağı) vb. izlemiştir. 1968 yılında Fransa da başlayan ve daha sonsa Avrupa'nın önemli şehirlerine yayılan mayıs olayları birbirinden anlayış olarak farklı grupların çatışmalarına sahne olmuştur.

20. yüzyılın başında Avrupa da sıkı totaliter rejimler (faşizm, nazizm, Fransız rrkçı să̆ politikaları) güçlenip yayılmaya başlamıştır. Yönetimlerin baskısına dayanamayan çoğu sanatçı ve bilim adamı ülkelerini terk ederek ABD’ye göç etmiş̧ir. Bu göçün etkisiyle siyasi olduğu kadar kültürel olarak da güç kazanan $\mathrm{ABD}$, batı kültür tarihinde ilk defa merkezi bir otoriteye sahip olmuştur. $\mathrm{Bu}$ dönemde sanat dünyasında iki yeni olgunun oluştuğu görülmüştür. Bunlardan biri Amerikan resim okulunun ortaya çıkması, diğeriyse New York'un sanatsal yaratının merkezi haline gelmesidir. New York'ta müzecilik anlayışına önem verilmesi, izleyici sayısının artması ve bölgenin sunduğu olanaklar sanatın merkezinin Paris'ten New York'a kaymasına sebep olmuştur. Ayrıca, New York'un sanatçılar ve izleyiciler tarafından daha çok istek görmesi çağdaş sanatın daha çabuk benimsenmesini sağlamıştır.

1950'lerde savaş sonrası ekonomik büyüme, "tüketim toplumu" normlarını oluşturmuştur. Bununla birlikte kitle kültürü, popüler kültür yaygın bir şekilde belirginlik kazanmaya başlamıştır. Bu gelişmeye bağlı olarak, 1950'lerin sonunda Anglosakson ülkelerinde ortaya çıkan Pop-Art özellikle Richard Hamilton'un "Bugün Evlerimizi Böyle Çekici ve Farklı Kılan Nedir?" adlı çalışması ile ilk örneğini vermiştir. Popüler kültür ve kapitalizm 'in birlikte hareket ettiği bu dönemde, ABD'de oluşan pop sanat, ABD tüketim toplumunu model olarak almıştır. Andy Warhol, "Yeni mabedimiz süpermarketler" diyerek parayla sanatın örtüştüğünü bu sözleriyle dile getirmiştir. Popüler kültürün kapitalizmle birleşmesi yüksek kültür ile alt kültür arasında çatışmanın oluşmasına neden olmuştur. Yüksek kültür ve kitle kültürü arasındaki ayrımın belirsizleşmeye başlaması yüksek kültür savunucuları tarafından tepkiyle karşılanmıştır. Böylece iki kültür arasında karşıt kültürel kopuş meydana gelmiş̧ir.Gündelik yaşamın sanata yansıması başka sanatsal faaliyetleri de beraberinde getirmiştir. Yeni Realizm, Sitüasyonizm, Happeningler, Fluxus, Kinetik Sanat, Arte Povera (Yoksul Sanat), Yeni Figürasyon olarak adlandırılan bu sanatlar birbiri ardına oluşmuş ve birçoğu gündelik yaşama ait hareketler olarak ortaya çıkmıştır. Sanat ve yaşam iç içe geçmiştir. Örneğin, "Happening" sanat topluluğu, resmi tuval üzerine değil de, bir gösteri şeklinde halkla iç içe gerçekleştirmiştir. Sanat hayatın bir parçası haline gelmiş, sanat ve hayat arasında oluşan sınır ortadan kalkmıştır. Sanatçılar gösteri anında gerçekleşen eylemin kendisinin sanat eseri olduğunu iddia etmişlerdir.

Danto'ya göre pop sanat, gerçekliği hayal edilebilecek en alt basamağa iten Platon'un öğretisini altüst etmiştir. Platon'un öğretisi Devlet'in onuncu kitabında şöyle yer almıştır: "Burada Platon yatağın gerçekliğine dair üç kip tanımlar: İdea ya da form olarak, bir 
marangozun yapabileceği bir şey olarak ve sonra da formu taklit eden marangozu taklit eden ressamın yapabileceği bir șey olarak." Platon, sanatçıların bilgiden yoksun olduğunu, onların sadece görüntülerin görüntüsünü bildiklerini savunmuştur. 1960'ların sanat dünyasında ise gerçek yataklar tuval üzerinde görülmeye başlamıştır. Böylece sanatçılar sanat ile gerçeklik arasındaki uçurumu kapatmaya çalışmışlardır. Ancak sonrasında, bunlar gerçek yatak ise onları sanat yapan nedir? sorusu gündeme gelmiştir. Böylece sanat ile gerçeklik arasındaki farkın görsel olarak kavranamayacağı ortaya çıkmıştır. Sanat, pop aracılığıyla kendine dair doğru felsefi sorunun ne olduğunu bulmuştur. Birbiriyle aynı olan, iki şey arasında farkı oluşturan şey nedir? Aynı dönemde, Robert Rauschenberg sanatın gerçeklikle ilişkisini eleştirel bir bakış açısıyla sorgulamış, sanat eseri ile eşya arasındaki farkı sıfırlamaya çalışmıştır. Bu gelişme 1960'larda oluşan Pop hareketin habercisi olmuştur. Böylece sanat ve medya, sanatçı ve kitle arasındaki sınırların belirsizleșeceği, farklılıkların giderilebileceği ve elbette artık gerçeğin üretilmiş modellerden (taklidin taklidi - simulacrum) oluşturulabileceği bir döneme girilmiştir. Değiş̧en bu sanat anlayışları, 1960'lı yıllarda sanat felsefecileri ve sanatçılar tarafından düşünülen asıl soruyu ortaya çıkardı: Sanat eğer kendini günlük hayatın nesnelerinden ayırt etmezse, ona artık sanat denilip denilmeyeceğiydi. Bu soruyu, Amerikalı ressam Jasper Johns, sanatsal gerçekliği ve resimlerin simgelerini sorgulamakla yanıt bulmaya çalışmıştır. Warhol ise bir makine gibi davranarak, eşsiz sanat nesnesinin yok olduğunu yerine içi boşaltılmış ruhsuzlaşmış bir sanatın geldiğini kanıtlamaya çalışmıştır.

1960'lar Dünya'da farklı sanat anlayışlarının ortaya çıktığı yıllar olmuştur. Pop Art, FotoRealizm, Minimalizm vb. Ayrıca, kadın sanatçıların eylemleri, sivil toplum örgütlerinin öğrenci, etnik, din, renk ve cinsiyet ayrımlarının dikkatleri çektiği toplumsal olaylar bu yıllarda ve daha sonrasında görülmüştür. 1960'dan sonra sanatın olağanüstü bir hızla değişim yaşadığı izlenmiştir. Bu değişim sanatın biçimsel yapısını ile birlikte düşünsel yapısını da etkilemiştir. Minimalizim, Kavramsal Sanat, Vücut Sanat1, Yoksul Sanat, Toprak Sanatı, Fluxus, Beuys'un eylemleri bu dönem de gerçekleşmiştir. Sanat, artık kendini kendisiyle sorgulayan, kendine ait tanımları yeniden ele alan, felsefenin asli görevi olan kavram üretmek işini üstlenmiştir. Sanatın böyle bir işlev üstlenmesi dil bilim, anlam bilim ve yapısalcılık gibi alanlarında önem kazanarak sanatın sorgulanmasında başvurulan kaynaklar olmasına neden olmuştur. Sanatın tanımı, sanat yapıtının anlamı ve sanatı kültürel bir öğe olarak çözümlemek ancak bu yöntemlerle gerçekleştirilmiştir. Sanatın kavramsallaşma sorunsalı, hiç kuşkusuz biçimsel sanat anlayışına da farklı bir anlam yüklemiştir.

Sanat alanında yaşanan bu değişimler 1917 yılında Marcel Duchamp'ın bir pisuarı duvara asması ve ona "Çeşme" adını vermesiyle başlamıştır. Ancak onu hazırlayan koşullarında en az onun kadar önemli olduğu bilinmektedir. Bu değişimi temellendirebilmek için Birinci Dünya Savaşı'nın öncesini ve yıkımlarla dolu sonrasını bakmakta fayda vardır. Savaş öncesi kapitalist sistem toplumun tüm alanlarında olduğu gibi sanatı da etkilemiştir. Sanat, kapitalist sınıfın kendini ve "kara" parayı aklamak için kullandığı bir araç haline gelmiştir. Savaşın sonunda ise, imparatorluklar yıkılmış, ülkeler pasaportla girilen, değişik kültür ve yaşam biçimlerinin egemen olduğu bölgeler haline gelmiştir. Sanat alanında ise sanatçılar yaşadıkları olumsuzlukları eserleriyle tepki vermişlerdir. Egemen sınıflarla ve kurumlarla alay etmiş, onları aşağılayan eserler ortaya koymuşlardır. Duchamp'ın çıkışı, Maleviç'in isyanı bu dönemde gerçekleşmiştir. Duchamp'ın "ready made" lerinden sonra enstalâsyonlar plastik sanatlar kavramını tuval resmi-heykel arasında sıkışmaktan kurtarmıştır. Ancak tüm bu oluşumları tek bir nedenle ya da sanatçı ile sınırlamak yanlış olur. Çünkü bu oluşumların hepsi özgürlük arayışı içinde birer bütündür. Bu arayışların altında yatan ana amaç sanatın sorgulanması olmuştur. Duchamp'la başlayan dada hareketi, Johns, Rauschenberg, Klein ve Manzoniyle süren yeni- dadacı çizgi ile farklı bir boyut kazanmıştır.

1960’lı yıllarda, geleneğe karş1 çıkmakla geleneği önemsemek arasında yaşanan çatışma minimal sanatı 'Boyasal Resim Sonrası Soyutlamac1 Resim' ile Pop Sanat arasinda bırakmıştır. Hasan Bülent Kahraman bu oluşumu geleneksel resim ile bağdaştırarak şöyle açıklamıştır; 
"Geleneksel tuval resminde yüzey, derinlik, perspektif, göz yanılsaması gibi sorunlar ă̆ırlıklarını sürdürürlerken bir şey iyice anlaşılmış ve kesinlik kazanmıştır. Boya resmi 'bundan böyle' de üretken ve devingen olmak istediği her noktada bunu kendi içine dönerek, kendisine eklemlenerek ve kendisiyle bütünleşerek başaracaktır. Biçim açısıından olsun, içerik açısından olsun resim ancak geleneksel sorularına yanıt aradıkça varsıllaşacaktı." (Kahraman, 1991: 64).

Dünya da özellikle batıda, toplumsal anlamda 1960 ve 1970'li yıllarda önemli değişimler yaşanmıştır. Marksizm yeniden gündemde ki yerini almış, hippilik, çiçek çocuğu olmanın bir yaşam biçimi olarak kabul edilmesi, Jean Paul Sartre'ın hakiki insan oluş felsefesinin kabulü, The Beatles topluluğunun konserlerini on binlerce kişi tarafından izlenmesi gibi. Daha öncede olduğu gibi sanatçılar kapitalist sisteme başkaldırmış, ahlaki değerlere, parasal ilişkilere, tarihe, dine hemen hemen her şeye isyan etmişlerdir. Bu gelişmeler sanata yansımış, kavramsal sanat içerikli performans ya da vücut sanatı olarak kendini göstermiştir. Wittgenstein'in dilde indirgemeci yaklaşımı minimalistleri etkilemiştir. Bu etkilenme, onlarda form ve biçimde sadeliğe gitmekle gerçekleşmiştir. Aynı yıllarda Kosuth 'Felsefeden Sonra Sanat' adlı çalışmasını sergilemiş, Weimer ve Barry 'Dil ve Sanat Gurubunu kurarak dilsanat-kavram ilişkisini sorgulamıştır. Hasan Bülent Kahraman bu oluşumu şöyle açıklamıştır;

"Sanatçı yapıttyla felsefecinin ya da belli bir felsefenin sözünü ve sözcülüğ̈̈nü üstlenmiş; felsefecide kendi görüşlerini temellendirebilmek için sanatçının yapıtına yönelmiştir. Biçim olgusunun sinırlart içinde kalmak yükümlülü̈̆̈̈ açılmış bağlam, önem verilerek öne çıkılmıştır. Sanatçı yapıtıyla, tarihselliği saptamak, toplumsal olanı tartışmak, güncel olana irdelemek, siyasal olan karşısında tavır almak istemiştir." (Kahraman, 1991: 64).

Kavramsal sanat, herhangi bir kavramı ele alarak onun özünü ve ortaya çıkış şeklini irdelemiş, yapıtı belli bir düşünceyi iletmek için sadece bir araç olarak kullanmıştır. Minimalizm ve Kavramsal Sanatın ABD'de ve Avrupa'da etkili olduğu 60'11-70'li yıllardan sonra, figüratif resim yeniden gündeme gelmiştir. Danto, yetmişleri kapsayan on yılda, tarihin yolunu kaybettiğini, çünkü fark edilebilir bir istikameti andiran hiçbir şeyin ortaya çıkmadığını söylemiştir. 1962 'de Soyut Dışavurumculuğun sona erişiyle birlikte hızla birbirini takip eden çeşitli üslupların görüldüğünü belirtmiştir. Bunlar, Renk Alanı Resmi, Sert Kenar Soyutlama, Fransız Yeni Gerçekçiliği, Pop, Op, Minimalizm, Arte Povera, ardından Richard Tuttle, Eva Hesse ve Barry Le Va'yı kapsayan yeni heykel ve onun ardından da Kavramsal Sanatın oluşumuydu. Sonra yine hareketsiz bir on yılın daha yaşandığını bu yıllarda görülen desen ve süsleme gibi münferit hareketlerin 1960'ların ayaklanmalarını ve üslupsal çeşitliliğini yakalayamadığını belirtmiştir. Seksenlerin başında yeni-dışavurumculuğun biranda yükseldiğini ve yeni bir istikametin yaratıldığı duygusunu yaşattığını söylemiş̧ir. Daha sonra, bu gelişmenin tarihsel istikamet adına fazla bir şey olmadığını, Yeni Dişavurumculuğun istikamet yanılsamasından ibaret olduğunun anlaşıldığını ileri sürmüştür. Yakın zamanda ise görsel sanatlarda anlatısal istikametin bulunmadığını ancak deneysel üretkenlik döneminin norm olarak yerleştiğinin hissedilmeye başlandığını söylemiştir (Danto, 2010: 36).

Kavramsal Sanat, modernizmde olduğu gibi güzellik düşüncesini yadsımış, yargı ve duyguların yasalaştığı evrensel bir varoluşa önem vermiştir. Bu nedenle tuval resminin biçimsel yapısı, yerini dil ve sembollere bırakmıştır. Sanatta görülen bu kavramsal varoluş 1980'li yıllarda yeni bir Rönesans'ın doğuşu ile son bulmuştur. Bu ilan 1980'li yılların, 1970'li yılları yadsımasının yanı sıra, modern sanata yöneltilen genel bir saldırı olarak da kabul edilmiştir. Enis Batur bu oluşumu şöyle açıklamıştır;

"Buna göre modernizm hiç olmamıştl. Dünyanın teknolojik harikalarla değişmiş olduğu yolundaki ütopyacı ham hayallerin ürünü, soyutlanmacı, fildişi kule yanlısı, her sanat biçiminin özerkliğini ve sanatın yalnızca saf sanat konularıla ilgilenmesini 
savunan; bütün inancın yenilik yaratma ve şaşırtma, aceleciliği yüzünden her türlü anlaml evrimi engelleyen bir dizi öncü girişimlere bağlayan ve yenilik yaratmada başarısız olan bir akımdl." (Batur, 2000: 42).

Modernizmin duygu ve estetik güzellikten yoksun olmasına yönelik yapılan eleştiriler, pek çok eğilim için çeşitli dönemlerde yapılmıştır. XIX. yüzyıl akademizmine karşı çıkan modernizm, 1960 sonrası aynı kaderi kendi yaşamaya başlamıştır. Bu döngü içinde "figüratif sanat hiçbir zaman ortadan kalkmamış, bu alanda sanatçıların saylsı soyut sanatla uğraşanlardan belki de daha çok olmuştur." (Batur, 2000: 43).

20. yüzyıla kadar sanatın iki önemli kıstası vardı. Bunlardan biri düzen, diğeri betimlemeye dayalı biçim anlayışı. Ancak 20. yüzyıldan sonra modernizmin savunduğu, makine estetiği ve endüstrinin, sanat mitosunu ortadan kaldırmasıyla başka bir boyuta varmıştır. Bundan sonra sanat eskiden yücelttiği değerlere karşı çıkmış, ancak endüstrinin değerlerini ve özelliklerini kabul ederek bu katılımı farklı bir şekilde yapmaya başlamıştır. Bu nedenle modernizmin başlama noktasının burası olduğu kabul edilmiştir. Modernizmle birlikte ortaya çıkan kavramlar, 20. yüzyıl boyunca sanatı biçimlendirmiştir. Teknolojinin gelişmesi ile birlikte fotoğraf makinesinin icadı sanatın betimlemeci işlevini ikinci plana itmiştir. Ve sanatçının bu yöndeki başarısı anlamsız olarak kabul edilmiştir. Bunun sonucunda görsel anlatım yerini, duyusal ve kavramsal anlatıma bırakmıştır. Örneğin Picasso, üçüncü boyutu yanılsama olarak değil de kavram olarak anlatmak istemiştir.

Makinenin üretim süreci insanın kendi dünyasında kurduğu tutarlı ve ussal düzeni değiştirmiş̧ir. Çünkü makinenin üretimi, kabul edilen bir sıralamanın ötesinde bir sıralamayı sunmuştur. Bu oluşum betimlemeyi yok ettiği gibi, tekniğin ötesindeki düzeni de yok etmiştir. Sonucunda kompozisyon ortadan kalkmıştır. Yani alışılagelen biçimsel öğelerin birbiriyle olan ilişkisi sonucu ortaya çıkan ve buna verilen değer artık yok olmuştur. Bunun yerine, makine estetiğinin oluşturduğu düzen kabul edilmiştir. Makine, sanat ortamında alış1lagelen geleneksel düzen ve kompozisyon anlayışını yok etmiştir. Modernizmde, endüstriyel üretim ve yeni malzemeler ile gerçekleşen biçim-içerik bağımsızlığı sanatta kabul edilen evrensel dile olan inancı da ortadan kaldırmıştır. Sanatın içinde oluşan bu değişim batı kültürünün kendi yapısı ve kurallarının artık eskisi gibi olmadığının bir göstergesi olmuştur.

Modernizme bağlı bu gelişmeler sonucunda, geleneksel sanatın o güne kadar geçerli olan tüm kuralları yıkılmıştır. Bunun yerine yüzyılın ilk yarısında yıkılan bir dünyayı yeni keşif ve yaratımlarla yeniden inşa etme çabası başlamıştır. 1950'lere kadar çeşitli izm'lerle gerçekleştirilmeye çalışılan bu çaba, kendini genellikle manifestolarla, tek çare olarak sunan bu akımların sanatı anlam ya da biçim olarak tek bir doğruya bağlamak istemeleriyle sürdürülmüştür. 1950 sonrasında ise Pop Sanat ile gelişen ve gündelik yaşama bağımlı ilişkiler kuran sanat, gündelik yaşamın ifade ve davranış biçimleri ile arasında köprü kurmuştur. Bu oluşum, sanatın bağımsızlığı üzerine gelişen kuramlarını da sarsmıştır. II. Dünya Savaşı'nın ardından batı ülkelerinin siyasal alanda içten parçalanması ve üçüncü dünya ülkelerinin onlara karşı gösterdikleri tepki yeni bir anlayışın oluşmasına neden olmuştur. Bu oluşum, sanatta estetik gerçeklerin tek yönde oluşamayacağı gerçeğini gündeme getirmiştir. Sonuç olarak, 1960'ların sonunda, batı sanatı çok değerlilik ve kuralsızlık içinde sanatını inşa etmiştir. Bu dönemde resim, heykel, mimari ve yazı gibi çeşitli sanatlar arasında sınır kalkmış ve sanatçının esinlendiği konu, üslup ve teknik gibi biçimsel özellikler de yok olmuştur. Resim sanatında değer yargılarının yok olması, sanatçının biçimsel tercihlerinin estetik seçimi yerine, anlam üretiminin yönlendiriciliğine doğru kaymıştır. Bu nedenle herhangi bir sanat ürününde görülen biçim uygulamalarının altında ya kavramsal ya da içerikle ilgili niyetler vardır (Erzen, 2003: 1-7). Biçim ölçülerinin yok olması sanatta büyük bir özgürlüğün oluşmasına neden olmuştur. Sanat ve sanat olmayan arasındaki ayrımın belirsizliği eleştirel tavrın çözülmesi ile son bulmuştur. 1970'lerde kavramsal resim ile varlık gösteren sanat, dil tarafından kuşatılmıştır (Giderer, 2003: 158). Modernliğin anlamı ve 
modernizmin doğası üzerine tartışmaların yoğunlaşması ona olan güvenin son bulmasına neden olmuştur.

"Modernizm ile birlikte geleneksel olanın, dinin, aile ve diğer toplumsal kurumların sorgulanması sonucunda ortaya çıkan kimlik yıkımı; kapitalizmin bireyi yok eden, kendine yabancılaştıran; günlük yaşamı sığlaştıran işleyişi sonucunda parçalanan özne, artık konuştuklarının gerçekliğinden emin değildir." (Giderer, 2003: 177).

Teknolojik gelişmeler sonucunda seri üretimin artması, sanatı da etkilemiştir. Minimalizm ve Pop Art hazır yapıtları sadece konu alarak değil, biçimsel olarak da kullanmışlardır. Minimalizm ve Pop Art var olmadan öncede serilerin var olduğu bilinmektedir. Bu yöntem, sanata eski kuralların (sanatsal deha, tanrı, saf doğa, Platoncu biçimler gibi) yok olmaya başladığı anda nüfuz etmiştir. Böylece, sanatçının eserlerinin sınırsız bir serinin durdurulmuş bir anına dönüşmesi, onları dünya ile ilişkilerinden koparıp sanatçının diğer resimleri ile ilişki içinde olmasına neden olmuştur. Sanatın, eski kurallarını, diğer etmenlerden daha çok aşındıran serileşme hali, endüstriyel üretimden önce fazla değildir. Claude Monet'den Jackson Pollock'a Minimalizm, temsili sanattan, seri üretim sayesinde kurtulmuştur. Sanatçılar, o güne kadar doğadan ironik olarak özgün izlenimler çıkarmışlardır. Sanatta seriliğe boyun eğmek soyutlaşmanın temelini oluşturmuştur. Ancak soyut sanatta bile serilik, eserin teknik üretimi ile ilgili motifin resimsel düzenlenişine bağlı olarak varlık göstermiştir. Soyutlama, iptal ettiği betimlemenin sadece bir parçasını saklamıştır. Simulacrun yani tekrarlama ise betimlemenin göstergesel mantığını ortadan kaldırmaya çalışmıştır (Foster, 2009: 93-94).

Minimalizm ve Pop serileri, endüstriyel biçimleri ifade edip, onları eskiden uzak oldukları sanat, eğlence gibi alanlara yerleştirerek, kapitalist üretim ve tüketimin belirteci olmuşlardır. Toplumsal yaşamın tüm sektörlerine yayılmış olan standartlaşma, aşırı uzmanlaşma ve emeğin parsellenmesi gibi özellikler hem Minimalizm de, hem de Pop Art'ta görülmüş ancak bazılarına direnilmiş, bazılarına ise kendi çıkarları doğrultusunda kullanmışlardır. Minimalizm ve Pop'un oluşturduğu sanatsal dönüm noktası, 1960'larda gerçekleşen toplumsal, ekonomik, sosyal ve politik alandaki değişimlerle de ilişkilendirilmiştir.

Kapitalizm de, sanatın paraya dönüştürülmesi, sanatın sonsuzluk olarak adlandırılan gizli gücünü ortadan kaldırmıştır. Günümüzde sanat tamamen içinde bulunduğu dönemi yansıtmıştır. Bu durum Pop sanat ile ortaya çıkmıştır. Sanat zamansızlık gibi bir kavramın öne sürülmesinden rahatsızlık duymuş ve böylece idealizmini de yitirmiştir. "Başka bir deyişle, sanat (yalnızca sanat pazarının finansal bakış açısıyla değil aynı zamanda estetik değerlerin idare edilmesiyle de) borsa simsarlığının genel seyrine dâhil olmuştur." (Baudrillard, 2000: 91). Minimalist sanatın sonlanması, 1960'larda liberal ruha karşı olan iç çevreler ve onların para hırsı olarak gösterilebilir. Minimalizm, 1970'lerin sonlarında birçok sanatçı için maddi kazanç sağlayan bir akım haline gelmiştir. Bu nedenle Kavramsal Sanat, sanat nesnesini ortadan kaldırarak bunu engellemeye çalışmış ama bir süre sonra kendisi de sanat pazarının içine girmekten kurtulamamıştır. Pazar, bu ürünleri kitaplaştırarak, müzik kayıtlarını toplayarak, fotoğraf ve video çekimleri hazırlayarak satmayı başarmıştır. Resim sanatında, 1970'lere kadar süren formalizmin ardından 1980'lerde yoğun bir şekilde figüratif sanata geri dönüş yaşanmıştır. Bunun başlıca nedenleri Greenberg'in önderliğinde biçimcilik anlayışına karşı sanat çevresinde duyulan tepki ve 1980'lerde görülen sosyo-ekonomik gerçeklerde meydana gelen değişimlerdir. II. Dünya savaşından sonra ortaya çıkan sanat pazarı, sanatı bir metaya dönüştürerek kültür endüstrisinin malı haline getirmesidir. 1980'li yıllara gelindiğinde değişen sosyal ve kültürel ortam, sanatın yeniden biçimsel açıdan varlık göstermesine neden olmuştur. Bu oluşum Kavramsal Sanatın sanat nesnesini yok saymasına karşı gelişen tepki ile modernizme olan güvenin son bulması ile hız kazanmıştır. 


\section{Sonuç}

Sonuç olarak, sanat yapıtı kapitalist toplumda meta durumuna düşmekten kurtulamamıştır. Ancak sanat, varlığını her şeyden önce yine sanata borçludur. Sanat kuramcısı Arnold Hauser de buna ilişkin olarak, ön örneksiz ve öncesiz (yani sıfırdan başlayan) bir sanatçının üretiminin niteliğinin ne olacağını kestirmenin mümkün olmadığını belirtmektedir. Ona göre eserin, gerçeği ya da ressamın ruhunun derinliklerini ifade etmesinin sanat yapıtının alışagelmiş uygulamaları ya da geçerli kullanımları asla bütünüyle dışlayamaz. (İskender, 1990: 25).

Hauser'in de belirttiği gibi, her sanatçı, sanat yaşamının başlangıcında kendinden öncekileri örnek almıştır. Onların araç, yöntem ve amaçlarını iyi tanıyıp belli bir dönem kullanmıştır. Varlığını her şeyden önce kendinden önceki örneklere borçlu olan sanat, geçerli genellemelere dayanan ifade ve temsil etme biçimlerini kullanmak zorunda kalmıştır. 1980'li yıllarda, figüratif resme geri dönüşün nedenlerinden biri modernizme olan güvenin son bulmasıdır. Modernizm, makine estetiği ve endüstrisinin savunuculuğu nedeniyle sanatın eski mitosunun ortadan kalkmasına ve alışılagelen geleneksel düzen ve kompozisyon geleneğinin yok olmasına sebep olmuştur. Ayrıca yüzyılın ilk yarısında yıkılan bir dünyayı yeniden inşa etmeye çalışan yeni keşif ve yaratımlar, tek tip bir modelin ortaya çıkmasına neden olmuştur. Modernizm ile birlikte geleneksel olanın sorgulanması kimlik yıkımına, bireyin topluma ve kendine yabancılaşması sorununu beraberinde getirmiştir. Modernizme bağlı bu gelişmeler, geleneksel sanatın tüm kurallarını yıkmış, sanatı anlam ve biçim olarak tek bir doğruya bağlamak istemiştir. Modernizm sonrası resim, popüler kültürün etkisiyle kuru, katı düşünsel sınırlar içinde varlık gösteremeyeceği anlaşılmıştır. Özellikle 1980'lerde resmin mitolojik ve mistik anlayışı tekrar önem kazanmıştır. Kavramsal sanattan sonra sanat, bir kez daha figüratif resme geri dönerek duygunun ve estetik güzelliğin farkına varmıştır.

\section{Kaynakça}

Batur, E. (2000). Modernizmin Serüveni, (4. Bask1), İstanbul: YKY.

Baudrillard, J. (2000). Sanatın Komplosu, (Çev: Cem İleri), Sanat Dünyamız, Sayı, 76.

Danto, A. C. (2010). Sanatın Sonundan Sonra, (Çev. Zeynep Demirsu),(1.Basım), İstanbul: Ayrıntı Yayınları.

Erzen, L. N. (2003). Modernizm Sonras1 Sanat, http://www.felsefeekibi.com

Foster, H. (2009). Gerçeğin Geri Dönüşü, (Çev. Esin Hoşsucu), (1. Basım), İstanbul.

Giderer, H. E. (2003). Resmin Sonu, Ankara: Ütopya Yayınevi.

İskender, K. (1990). Hangi ya da Nasıl Bir Yeni ve de Ne Yapmalı? Sanat Çevresi, Sayı, 143.

Kahraman, H. B. (1991). Sanatta Konvansiyonel Tradisyone İlişkisinbakışlar: ResimKavramsal Sanat Açısından, Hürriyet Gösteri, Sayı,125. 